\title{
RESEARCHPAPER
}

\section{Optimization studies for algae biofuels production}

\author{
PRATEEK SINGH ${ }^{1}$, DHEEBAN CHAKRAVARTHI KANNAN ${ }^{2}$, VINEETA GURNANI ${ }^{1}$, ARADHANA \\ IRENE CHARAN $^{1}$ AND AMIT ALEXANDER CHARAN ${ }^{1}$
}

\author{
${ }^{1}$ Department of Molecular and Cellular Engineering, Sam Higginbottom Institute of Agriculture, Technology and \\ Sciences, ALLAHABAD (U.P.) INDIA \\ ${ }^{2}$ The Energy and Resources Institute, NEW DELHI, INDIA \\ Email : prateek0783@gmail.com
}

Article Info :Received : 05.12.2015; Revised : 08.01.2016; Accepted : 07.02.2016

Continuous use of fossil fuel is globally considered as unsustainable because of depleting supplies and these fuels also account for accumulation of green house gases in the environment. Renewable, carbon neutral, transport fuels are necessary for environmental and economic sustainability. Microalgae feedstocks are gaining interest in the present day energy scenario due to their fast growth potential coupled with relatively high lipid, carbohydrate and nutrients contents. All of these properties render them an excellent source for biofuels such as biodiesel, bioethanol and biomethane; as well as a number of other valuable pharmaceutical and nutraceutical products. It's a carbon neutral fuel. But high production cost is still a big hurdle in its commercialisation. Various optimisations are discussed in this research for the commercialization of algal biofuels. The production cost of algal biofuel is still quite high, so a lot of optimisation studies for growth parameters, lipid productivity and lipid extraction process are needed, which are discussed in this study. Commercialization of microalgae for biodiesel is technically feasible. Studies had shown that algae biofuel has the potential to completely displace liquid fuels derived from petroleum. Economics of producing microalgal biodiesel need to improve substantially to make it competitive with petrodiesel, but the level of improvement necessary appears to be attainable.

Key words : Microalgae, Biofuels, Nutraceutical, Biomass, D. tertiolecta, D. salina

How to cite this paper: Singh, Prateek, Kannan, Dheeban Chakravarthi, Gurnani, Vineeta, Charan, Aradhana Irene and Charan, Amit Alexander (2016). Optimization studies for algae biofuels production. Asian J. Bio. Sci., 11 (1) : 42-48 [Special Issue of AFBSAH-2016]. 